\title{
Análise de fotos de guerra e impactos emocionais decorrentes em termos da atenção visual ${ }^{1}$
}

Leão Serva'

http://orcid.org/0000-0003-0530-2481

Eduardo Eugenio Spers"

http://orcid.org/0000-0002-8057-3460

Norval Baitello Jr'II

http://orcid.org/0000-0001-7814-7633

\section{Carlos Augusto Costaiv}

https://orcid.org/0000-0001-7440-7856

I - ESPM-SP

São Paulo (SP). Brasil.

II - Universidade de São Paulo.

Piracicaba (SP). Brasil.

III - Pontifícia Universidade Católica.

São Paulo (SP). Brasil.

IV - Instituto Universitário de Lisboa. Lisboa. Portugal.

Resumo: O artigo se insere nos estudos sobre "Fórmulas da Emoção na Fotografia de Guerra", que buscam identificar elementos causadores de impacto emocional nas imagens de conflito contemporâneas. No presente 
estudo, usamos de forma complementar três experimentos pragmáticos para explorar as reações dos observadores às imagens de conflito: ferramenta de reconhecimento de emoções por expressão facial; questionários de pesquisa quantitativa; e mecanismo de identificação do movimento ocular (Eye Tracking). Entre os resultados apresentados, destaca-se a curva crescente de engajamento durante todo o período de apresentação da sequência de imagens, sugerindo a possibilidade de que as imagens criem alguma forma de necessidade. O resultado do estudo com Eye Tracking mostrou que o rosto das pessoas retratadas é sempre o foco primordial de atenção.

Palavras-chave: fotografia de conflito; reconhecimento facial; emoções; Aby Warburg; vício; Eye Tracking.

\begin{abstract}
Analysis of war photos and resulting emotional impacts in terms of visual attention - This paper is part of the studies on "Formulas of Emotion in War Photography", which seek to identify elements that cause emotional impact in contemporary images of conflict. In the present study, we used three pragmatic experiments, in a complementary way, to explore the reactions of the observers to the images of conflict: a tool for recognizing emotions by facial expression; quantitative research questionnaires; and eye movement identification mechanism (Eye Tracking). Among the results presented, the increasing engagement curve stands out during the entire presentation period of the image sequence, suggesting the possibility that the images create some form of addiction. The result of the study with Eye Track showed that the faces of the people portrayed are always the primary focus of attention.
\end{abstract}

Keywords: war photography; facial recognition; emotions; Aby Warburg; addiction; Eye Tracking.

\title{
Introdução
}

Este artigo se insere em um conjunto de estudos sobre imagens de guerra e seus efeitos sobre os observadores. Partimos da premissa, conhecida, de que coberturas de conflitos são geradoras de demanda de consumo de mídia. Desde o seu nascimento, o jornalismo de guerra se estabelece em conjunto com a fotografia e, desde o primeiro jornal a cobrir um conflito bélico (na Criméia, 1853-1856) até os sites noticiosos e tevês por assinatura do século 21, a cada cobertura, cresce a audiência, multiplicam-se as receitas (SERVA, 2017, p. 22).

Neste estudo, buscamos detectar empiricamente as reações emocionais despertadas pela visão de imagens de guerra e identificar quais os elementos das imagens que concentram o olhar do espectador, as áreas da imagem que denominamos "pontos de atenção". Reservamos para um trabalho posterior a exploração das possíveis coincidências entre "pontos 
de atenção" e "fórmulas de emoção", conforme o conceito criado por Aby Warburg (2013, p. 436).

Como forma de pesquisar o objeto, adotamos a integração de três métodos empíricos complementares:

1.Uma análise das emoções despertadas pelas imagens de conflitos ou semelhantes nos espectadores, usando equipamentos de reconhecimento facial;

2.Uma pesquisa quantitativa com declaração dos entrevistados sobre as emoções que sentiram ao observar imagens de conflitos ou semelhantes;

3.Uma análise das áreas ou elementos dentro das fotografias de guerra que atraem a atenção dos observadores, usando equipamento de Eye Tracking.

Mais adiante, relatamos os resultados dos três estudos conforme a ordem de sua realização.

\section{Referências dos estudos de expressão das emoções}

Treze anos depois de publicar A Origem das Espécies, obra que iria consagrá-lo como um dos maiores pensadores da história, ao revolucionar o conhecimento sobre o desenvolvimento das espécies animais, Charles Darwin escreveu outra obra seminal: A Expressão das Emoções nos Homens e nos Animais (1872). O estudo mostra como gestos expressivos de emoções se repetem em animais e homens, de tal forma que podem ser considerados sinais da evolução humana com função atenuada, por assim dizer: expressões de medo contêm ritualizados os gestos de defesa diante de uma agressão; o gesto de um sorriso usado como saudação à chegada de uma outra pessoa simula o gesto arcaico de mostrar os dentes em sinal de paz.

Já desde o início de sua pesquisa, Darwin concebe os gestos de emoção como forma de interação, crucial não só para os estudos das emoções em si (psicologia, psiquiatria) mas também para as ciências da comunicação: as expressões supõem transmissão dos sentimentos e, portanto, sua percepção por outros indivíduos. Darwin cria um método científico de análise do reconhecimento das expressões a partir do conjunto de fotos feitas por Guillaume Duchenne de Boulogne (1806-1875). O neurologista francês queria identificar exatamente os músculos envolvidos nas expressões do rosto. 
Para isso, fazia experiências com vítimas de paralisia facial, que submetia a choques em músculos específicos do rosto, provocando artificialmente gestos expressivos de emoção. Duchenne fotografava as expressões de seus pacientes. Darwin, como narra no início de seu livro, fez um levantamento dos trabalhos mais relevantes existentes até então sobre o assunto e procurou Duchenne. O francês deu a ele uma cópia de suas fotografias, que compunham uma espécie de dicionário de gestos faciais expressivos.

A partir desse conjunto de fotos, Darwin concebeu seu método empírico, composto por seis passos: 1) observar as crianças, "pois elas exibem um grande número de emoções", "com grande intensidade"; 2) estudar os loucos, "pois eles são dados às mais intensas paixões e as manifestam sem nenhum controle"; 3) apresentar as fotos produzidas por Duchenne a pessoas de diferentes idades e ambos os sexos, perguntando que emoção sentia a pessoa quando foi fotografada; 4) buscar expressões de emoções em rostos retratados em pinturas e fotografias de grandes mestres das artes; 5) observar diretamente nativos, especialmente os que mantinham pouco contato com europeus, para entender se "encontramos as mesmas expressões e gestos nas diferentes raças humanas"; 6) por fim, analisar a expressão de emoções em animais comuns, pois com eles "estamos menos propensos a nos deixar influenciar pela nossa imaginação e podemos estar seguros de que suas expressões não são convencionadas" (DARWIN, 2013, p. 24).

Para realizar o objetivo dos passos de números 3 e 5, Darwin enviou, em 1867, as fotos expressivas produzidas por Duchenne para pessoas de locais diferentes, pedindo que elas interpretassem as emoções sentidas pelas pessoas fotografadas. No caso dos nativos com pouco contato com europeus, enviou para pessoas que trabalhavam junto a grupos tribais de recente contato.

A partir dos resultados do passo número 3, Darwin diz que "muitas das expressões foram imediatamente reconhecidas por quase todos, ainda que descritas não da mesma maneira" (idem, p. 20). E, a partir dos resultados do passo número 5, afirma a universalidade dos sentimentos expressos por movimentos do rosto humano.

Como já tinha ocorrido com $A$ Origem das Espécies, sua revolucionária obra anterior, A Expressão das Emoções no Homem e nos Animais foi objeto de polêmicas por cerca de cem anos após seu lançamento. Ao longo desse período, diferentes estudiosos debateram, a favor ou contra, o trabalho de Darwin, com diferentes abordagens sobre a capacidade de compreensão 
das emoções de outros espécimes (e mesmo entre espécies), uma vez que Darwin estabelecia a coincidência dos movimentos musculares faciais para a expressão de emoções semelhantes, o que vale para sinais de alegria, medo ou agressividade.

A capacidade de captar o sentimento contido nos gestos de outros viria a ser definida como empatia por Theodor Lipps (1851-1914), que cunhou o termo no início do século 20. "'Ficamos em suspense ao assistir à apresentação de um funâmbulo', afirmou Lipps, 'porque indiretamente entramos em seu corpo e participamos da sua experiência, nos sentimos na corda bamba com ele"' (apud FRANS DE WAAL, 2010, p. 98). Para definir essa capacidade de participar da experiência do outro, Lipps lançou mão do grego, usando o termo empatheia, "que significa 'experimentar forte afeto ou paixão"', "transmite a ideia do movimento de um indivíduo projetando-se no interior de outro". E explica como se realiza, por meio dela, uma forma de comunicação: "A empatia oferece acesso direto ao 'outro eu"' (Ibidem).

Contemporâneo de Lipps e tendo acompanhado seus estudos sobre empatia, o alemão Aby Warburg (1866-1929) concebeu a ideia de que a capacidade de perceber o sentimento do outro também acontecia pela imagem, o que ele aplicou à arte, da Antiguidade ao Renascimento: "Para ele, o gesto, concebido como a manifestação de uma determinada vontade de expressão genuína, se converte em uma imagem física e dinâmica cheia de significado" (WARBURG, 2012, p. 30).

Quando o livro de Darwin estava para completar 100 anos, nos anos 1960, o cientista norte-americano Paul Ekman, que vinha estudando gestos corporais expressivos de emoção em pacientes de neurose ou psicose, decidiu estudar também as expressões faciais. Influenciado por estudos antropológicos e sob orientação de Margaret Mead e Gregory Bateson, entre outros, Ekman iniciou os estudos de expressões faciais acreditando que elas são transmitidas socialmente e, portanto, variam conforme a cultura de cada povo. “Eu sabia que Charles Darwin tinha afirmado exatamente o oposto, mas eu estava tão convencido de que ele estava errado que eu nem mesmo me dei ao trabaIho de ler seu livro", escreve Ekman em seu Emotions Revealed (2003, p.19).

Ekman produziu um painel de fotografias de pessoas com expressões de diversos sentimentos e as apresentou para habitantes de diferentes países (Chile, Argentina, Brasil, Japão e Estados Unidos). Todos identificavam as emoções expressas nos rostos fotografados. Isso, no entanto, poderia permitir 
a conclusão de que o reconhecimento se devia ao fato de todos os entrevistados terem uma cultura urbana cosmopolita. Ekman, então, analisou filmes produzidos sobre o dia a dia de uma cultura indígena isolada, os Fore, uma tribo do arquipélago de Papua Nova Guiné. Ele conta que não encontrava nas expressões de seus rostos nenhuma emoção que não coincidisse com aquelas que conhecia. Ao final de várias fases de estudos, o levantamento constatou que eles reconheciam os sentimentos que as pessoas expressavam quando foram fotografadas, menos para os dois sentimentos, medo e surpresa, que os pesquisados tendiam a confundir.

Sua conclusão, de que os gestos expressivos são universais, foi apresentada na conferência anual da sociedade norte-americana de antropologia de 1969. O desenvolvimento do trabalho de Ekman nas décadas posteriores teve grande influência sobre diversas áreas da psicologia e da neurologia. No final dos anos 1970, ele desenvolveu o que descreveu como "atlas do rosto", chamado FACS (Facial Action Coding System), com descrições em palavras, fotografias e filmes sobre como medir movimentos faciais expressivos de emoções em termos anatômicos. Curiosamente, a essa altura, no fim do século 20, o trabalho de Ekman replicou outro componente da trajetória de Darwin, as pranchas de Guillaume Duchenne, de quase 150 anos antes.

Em seus estudos, nos anos 1970, Ekman identificou seis emoções básicas, cuja expressão é universal: tristeza, surpresa, repugnância, raiva, medo e alegria. Esses impulsos podem ser combinados ou mitigados, aparecendo com menor clareza quando os sentimentos são menos intensos ou mais sofisticados. Nos anos 1990, Ekman propôs uma lista maior de emoções básicas, sempre identificadas com expressões faciais. Trabalhando com pressupostos e conclusões semelhantes, embora paralelamente a Ekman, o psicólogo norte-americano Robert Plutchik propôs, em 1980, a existência de oito emoções básicas (além das seis de Ekman, acresceu "confiança" e "antecipação" ou intuição) e 24 "primárias", "secundárias" e "terciárias", compostas da combinação de emoções básicas. Com isso, ele construiu um diagrama, na forma de uma rosa dos ventos, que se tornou referência nos estudos do gênero.

Nos anos seguintes, o FACS proposto por Ekman e outras variações semelhantes serviram de base para o desenvolvimento de diversos sistemas de reconhecimento computadorizado de emoções expressas pelos movimentos do rosto, com uso em várias áreas da atividade humana, do 
neuromarketing (para avaliação de produtos, publicidades e filmes) até o treinamento de profissionais de controle de migração em aeroportos e agências de contra- espionagem. Neste estudo, usamos uma dessas tecnologias para reconhecimento de emoções despertadas pela visão de fotos de conflito.

Ao longo do século 20, os estudos iniciados por Duchenne, Darwin e Lipps, depois aprofundados por Paul Ekman e Plutchik, a partir dos anos 1960, tiveram grande desenvolvimento, principalmente a partir da década de 1990, com a revelação da empatia involuntária, em estudos do psicólogo sueco Ulf Dimberg, como sintetiza De Waal:

Dimberg demonstrou que a empatia não depende da nossa decisão. Nós simplesmente sentimos a empatia. Depois de fixar pequenos eletrodos no rosto de seus sujeitos de forma a registrar os mínimos movimentos musculares, Dimberg apresentou a eles numa tela de computador, fotografias de expressões faciais felizes e zangadas. Os humanos franzem o cenho em resposta a expressões faciais zangadas e erguem os cantos dos lábios em reação a expressões faciais felizes. [...] Perguntados sobre o que tinham visto depois dessa apresentação subliminar, os sujeitos não eram capazes de dizer coisa alguma sobre as expressões felizes ou zangadas, mas as haviam reproduzido mesmo assim. (DE WAAL, 2010, p. 99-100)²

Inspirados por Dimberg, na trajetória deste trabalho, também usamos a pesquisa quantitativa com questionário para respostas verbais sobre os sentimentos despertados pela visão das fotos, para comparar os resultados do teste de reconhecimento de emoções involuntárias com o relato que as pessoas fazem do que pensam ter sentido.

O entendimento dessa capacidade imediata e involuntária de compreensão da emoção alheia ganhou impulso também com a descoberta dos neurônios espelho, nos estudos dos pesquisadores da Universidade de Parma, na Itália, liderados por Vittorio Gallese. Em 1992, os cientistas italianos constataram que certas células do cérebro de primatas são ativadas quando eles observam uma ocorrência com outro animal da mesma forma que se comportam quando o próprio indivíduo observador é submetido pessoalmente a uma ação idêntica. Em outras palavras, ao assistir a um outro ser viver uma 
experiência já conhecida, certos neurônios de um macaco são ativados como se estivessem envolvidos diretamente no fato ${ }^{3}$. Trata-se de uma empatia absoluta, por assim dizer.

\section{Reconhecimento de emoções expressas pelo rosto}

Na trajetória desta pesquisa, realizamos um levantamento de natureza empírica sobre as emoções despertadas pelas fotografias de conflito, usando equipamento de reconhecimento de expressões faciais para identificar os sentimentos no momento da observação de um conjunto de imagens.

Para implementar o estudo, foi usada a ferramenta de reconhecimento de emoções desenvolvida pela empresa suíça NViso, que tem sede no Parque de Inovação da Escola Politécnica Federal de Lausanne (EPFL). Criada em 2009, como uma start up dedicada ao "desenvolvimento de sistemas de inteligência artificial para análise do comportamento humano usando análises de emoção", a empresa tem entre seus sócios Matteo Sorci, cientista com doutorado e pós-doutorado na EPFL sobre desenvolvimento de algoritmos de inteligência artificial dedicados a ensinar máquinas a interpretar emoções humanas através da análise de expressões faciais. O software de identificação das expressões emocionais criado pela NViso utiliza o FACS de Paul Ekman como matriz e classifica cada gesto facial conforme as seis emoções básicas definidas pelo psicólogo norte-americano: tristeza, surpresa, repugnância, raiva, medo e alegria. Seus relatórios identificam a expressão e a classificam quanto à intensidade do sentimento manifestado diante da visão de cada uma das imagens, apresentadas em sequência.

O estudo foi implementado pela NViso e sua parceira à época, a empresa brasileira de pesquisas FlyFrog/Perception, que selecionou os 120 sujeitos. A seleção das imagens de conflito foi feita por nós, para adequar o corpus da tese doutoral A Fórmula da Emoção na Fotografia de Guerra ao número de imagens compatível com a metodologia do sistema de reconhecimento facial da NViso, um total de 25 imagens.

Para as pesquisas com equipamento de reconhecimento de emoções expressas em gestos faciais, escolhemos 25 imagens. Além de fotografias contemporâneas de conflito, as imagens escolhidas incluíram obras de arte antigas, que contêm elementos que funcionam como fórmulas de emoção;

3 O estudo dos pesquisadores italianos liderados por Vittorio Gallese (2005). 
caveiras em uma gravura medieval e outra do Romantismo; a escultura "Pietá", de Michelângelo, e dois quadros de renascentistas com cenas de decapitação.

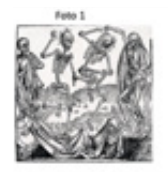

rotes 4

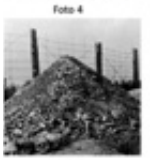

$\operatorname{sen} ?$
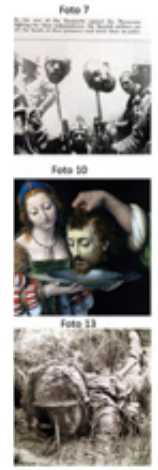
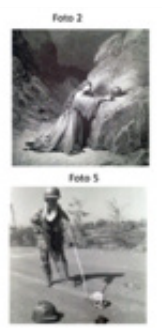

lnos
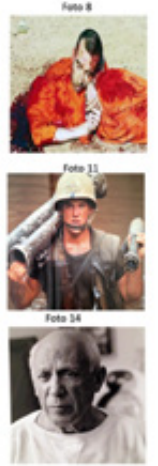
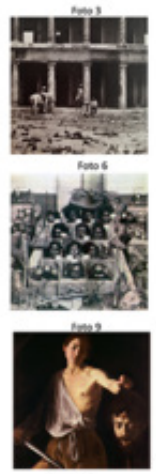

$\cos 12$

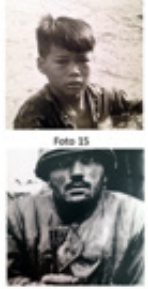

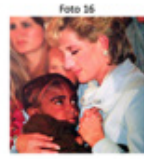

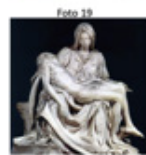

foto 22
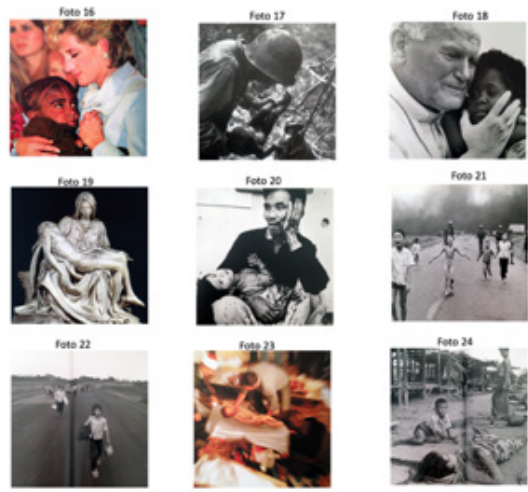

rote 24
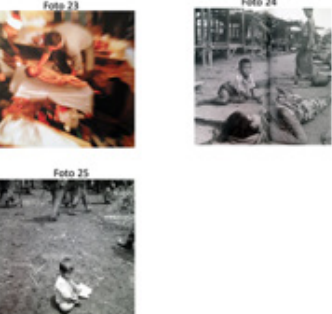

Figura 1. Corpus para reconhecimento facial ${ }^{4}$

As 120 pessoas selecionadas pela empresa FlyFrog para a realização do estudo foram segmentadas por gênero, idade e classe social. As 25 fotografias foram apresentadas em sequência, com 5 segundos cada foto (em um total de 125 segundos), projetadas em telas de computadores para cada uma das 120 pessoas. Em tempo real, a câmera do computador, ajustada para captar a imagem dos rostos, produziu um arquivo em movimento da reação expressa por cada rosto. $\mathrm{O}$ arquivo dessas imagens foi, então, analisado conforme o "dicionário", um conjunto de imagens de expressões faciais que identifica a emoção de cada pessoa. Ao final desse processo, a equipe liderada na Suíça pelo pesquisador Matteo Sorci produziu o relatório com a análise das emoções despertadas pela sequência de fotos, em curvas em que se pode identificar a reação a cada imagem e ao conjunto.

Nos gráficos, as reações emocionais são apresentadas em duas linhas, uma conforme suas curvas de intensidade, oscilantes conforme cada impulso ou

4 As legendas das fotos estão detalhadas antes das referências. 
imagem, e por uma linha média. O relatório aponta a fotografia que apresentou maior intensidade de cada emoção, distinguindo entre a fotografia que gerou o pico entre todas e aquela que coincidiu com o momento de maior média, o que nem sempre coincide.

O levantamento das emoções despertadas pelas imagens mostrou que o sentimento predominante foi o "engajamento"5 dos espectadores ao longo de toda a sequência das imagens. A tendência relativa à expressão de engajamento é uma curva ascendente pelos 125 segundos, com altos e baixos em função de cada imagem em si.

As duas fotografias que provocaram esse sentimento com maior intensidade envolvem imagens de crianças. São elas a famosa foto da menina vietnamita correndo em uma estrada após ter o corpo queimado por napalm e a de uma criança ferida que observa o corpo da mãe morta em uma explosão em um mercado na capital do Camboja, Phnom Penh, ambas durante o ciclo de envolvimento do exército norte-americano em guerras no Sudeste Asiático (nos anos 1970).

O sentimento de aversão ("Disgust") teve uma elevação irregular, uma subida seguida de queda e uma nova alta, que parece estar relacionada à imagem de uma criança com o braço retalhado, que observa a mãe, morta. Essas mesmas fotos aparecem entre as três imagens consideradas mais impactantes pelos sujeitos quando responderam ao questionário da pesquisa quantitativa.

O gráfico relativo à expressão "surpresa" produziu uma curva descendente, mas que começa e acaba com o mesmo patamar, que parece sugerir que os pesquisados vão se acostumando ao impacto das imagens violentas à medida em que a sequência de fotos avança. Duas fotos com crianças provocaram

5 O gesto facial apresentado foi identificado com a emoção básica "alegria". É um resultado aparentemente estranho porque as fotos da sequência não apresentam conteúdo emocional convergente com tal resposta emocional. Contudo, é necessário enfatizar que o padrão FACS utilizado pelo sistema realiza leitura de probabilidade de emoções primárias e é incapaz de interpretar emoções complexas, que podem ter certa similaridade com as contrações musculares que compõem a emoção alegria (visto serem secundárias, o sistema não pode identificá-las). Segundo Matteo Sorci (NViso), no caso deste estudo, a indicação "alegria", deve ser interpretada como engajamento em virtude de "intensa empatia". Em Emotions Revealed, Ekman comenta a dificuldade de identificar os sentimentos exatos manifestados por expressões faciais semelhantes às de alegria. "Creio que exista mais de uma dúzia de emoções prazerosas, cada uma universal, cada uma tão diferente das outras quanto tristeza, raiva, medo, repulsa e desprezo são umas das outras" (EKMAN, 2003, p. 207). No capítulo 9 do livro, ele passa, então, a definir as emoções que podem ser expressas por gestos semelhantes à "alegria", entre os quais: "Excitação, que é despertada como resposta para uma novidade ou desafio". E acrescenta: "Excitação tem seu sabor único (mas) embora possa ser sentida de forma isolada, frequentemente ela aparece misturada com uma ou mais emoções prazerosas. Excitação pode se misturar também com sentimentos de raiva, ira ou medo e terror" (idem, 210). 
mais surpresa (ou mais intensidade na manifestação dessa emoção): o Papa João Paulo $2^{\circ} \mathrm{com}$ uma criança negra em gesto de piedade se destacou entre todas. Também causou surpresa a foto de um bebê solitário, no Vietnã, que tem ao fundo uma tropa militar que marcha de costas para ele.

Já o sentimento de "tristeza" ("Sadness") apresenta uma curva consistentemente descendente, o que sugere essa redução do impacto à medida em que as fotos são apresentadas. A imagem que mais se destacou é a de um soldado norte-americano que carrega uma arma pesada durante a travessia de um curso de água e tem o semblante muito expressivo de tristeza ou apreensão.

Uma imagem arcaica se destacou na expressão de dois sentimentos, "raiva" e "medo": trata-se de uma gravura da "Dança dos Mortos" (tradição medieval, nascida à época das grandes pestes que assolaram a Europa), que mostra vários esqueletos representando a morte. O gráfico relativo a "raiva" é uma curva decrescente em que a imagem antiga se destacou junto com a criança palestina morta.

A curva de "medo" apresenta uma queda rápida seguida de uma subida e depois nova queda. Além da imagem medieval, destacam-se duas imagens de pessoas sentindo claramente medo, que tiveram índices de emoção semeIhante: o soldado norte-americano petrificado durante um bombardeio de sua base, durante a ofensiva do Teth, em uma imagem famosa do consagrado fotógrafo inglês Don McCullin, e a foto da criança vietnamita só, com soldados marchando atrás. É provável que mais do que sentir medo diante das fotos em si, os pesquisados tenham vivido uma manifestação clara de empatia, introjetando o sentimento que veem expresso nos rostos das duas pessoas fotografadas.

O estudo com reconhecimento das emoções expressas por gestos faciais sugere que o engajamento é crescente ao longo de todo o processo de exposição das imagens, em uma curva que independe da natureza ou média da imagem. Diante desse dado, levantamos a hipótese de que o engajamento é uma expressão de um possível vício provocado pela visão continuada das imagens violentas.

\section{Análise com questionário de pesquisa quantitativa}

Em seus estudos, Paul Ekman realizou, como controle para checagem de resultados, um estudo baseado em pesquisa quantitativa com questionário 
formado por perguntas que buscavam identificar as emoções que as pessoas declaravam sentir ao ver as imagens propostas. Sobre a natureza dos resultados obtidos face aos outros estudos de reações automáticas, ele afirma:

\begin{abstract}
A maior parte do que sabemos [sobre os eventos marcantes para as pessoas e sobre quando as emoções ocorrem] não vem da observação prática do momento em que as pessoas experimentam uma emoção ou outra. Em vez disso, vem de suas respostas aos questionários sobre quando se lembram de sentir uma ou outra emoção. O filósofo Peter Goldie ${ }^{6}$, em seu perspicaz livro, chama esse tipo de informação de pós-racionalização. [...] Nos questionários, há uma questão adicional do que as pessoas são dispostas a contar aos outros. Mas as respostas ainda podem nos ensinar bastante. (EKMAN, 2003, p. 39).
\end{abstract}

Cientes de que as reações "pós-racionalizadas" (cf GOLDIE apud EKMAN, 2003, p. 39) não refletem exatamente as emoções sentidas à visão das imagens, mas em busca daquilo que os questionários quantitativos "podem nos ensinar" (EKMAN, idem), como Ekman e Dimberg, decidimos também realizar um questionário de pesquisa quantitativa junto aos espectadores que foram submetidos à ferramenta de reconhecimento facial. Dessa forma, os 120 pesquisados foram questionados sobre as emoções que sentiram diante de 25 fotografias. Como afirma o cientista norte-americano, o resultado das respostas "pós-racionalização" discrepa daqueles identificados pelo sistema que "vem da observação prática do momento em que as pessoas experimentam uma emoção ou outra".

No questionário, os respondentes foram convidados a avaliar as imagens quanto ao seu impacto comparado e quanto às razões do impacto. Em resposta a essa questão, eles foram convidados a fazer a avaliação das fotografias quanto ao seu impacto, respondendo quais foram consideradas impactantes. Uma terceira pergunta pediu que cada respondente escolhesse em uma lista de emoções aquelas que sentiu para cada foto que identificou como impactante. As respostas formaram o ranking das fotos impactantes. Depois, deveriam marcar qual das fotos era a mais impactante.

As respostas indicam que a foto mais impactante de todas é a de uma vítima decapitada pelo Estado Islâmico (foto 8), sendo que 52\% dos entrevistados disseram ser a mais impactante de todas as fotografias. Entre os motivos apontados, estão o horror da decapitação, a brutalidade da morte, entre

6 Refere-se a GOLDIE, P., 2000, p. 47. 
outras. Três fotos de pessoas decapitadas foram elencadas entre as mais impactantes pelos sujeitos entrevistados, apesar das duas outras fotos (de números 6 e 7) serem antigas. O impacto da imagem de pessoas decapitadas é tão grande que mesmo uma pintura renascentista (foto 10) é apontada como uma das imagens mais impactantes da série.

Esses resultados comprovam as observações de Ekman e Dimberg sobre as diferenças entre as emoções sentidas imediatamente e a declaração "pósracionalização', uma vez que a foto mais impactante, segundo os entrevistados declaram, não aparece com o mesmo destaque entre as imagens que provocam emoções detectadas pelo sistema de reconhecimento facial.

A segunda foto mais impactante segundo os entrevistados é a de uma menina vietnamita ferida por napalm correndo e chorando de dor. A imagem, de 1972, tornou-se um clássico da Guerra do Vietnã, pela imagem empática do desespero da criança ao centro da fotografia. O resultado é imediato: 73\% dos respondentes destacaram a expressão das crianças como o elemento fulcral da fotografia.

Imagens de consolação são fortemente empáticas. É o que explica que quatro fotos de gestos de piedade envolvendo crianças apareçam na lista de imagens impactantes da série, com destaque ainda maior para a foto do pai vietnamita ferido que tem no colo o filho também ferido. "Impotência" (58\%), "angústia" (54\%) e "dor" (50\%) são as principais razões apontadas pelos entrevistados para explicar o impacto da fotografia.

Crianças provocam empatia, não só entre humanos mas em mamíferos em geral, como é sabido. As imagens em que elas aparecem como ponto fulcral, submetidas à violência da guerra, amplificam o impacto das emoções negativas, ainda que compaixão esteja entre os sentimentos citados pelos entrevistados sobre todas elas. "Angústia", "impotência" e "dor" se destacam diante da visão de crianças sofrendo em diferentes situações. Além da foto \#21, da menina nua vítima de napalm (considerada impactante por $71 \%$ dos entrevistados), outras três fotos de crianças aparecem entre as dez mais impactantes.

\section{Análise com Eye Tracking}

Depois de buscar a identificação das emoções despertadas de forma imediata pela visão de imagens de conflito e por declaração "pós-racionalizada" em 
questionário de pesquisa qualitativa, usamos a ferramenta de Eye Tracking para detectar quais as áreas das imagens concentram maior atenção do observador, que chamamos "pontos de atenção". O Eye Tracking permite analisar o movimento ocular dos observadores frente às fotografias e detectar quais elementos das imagens conseguem maior fixação visual (gaze points).
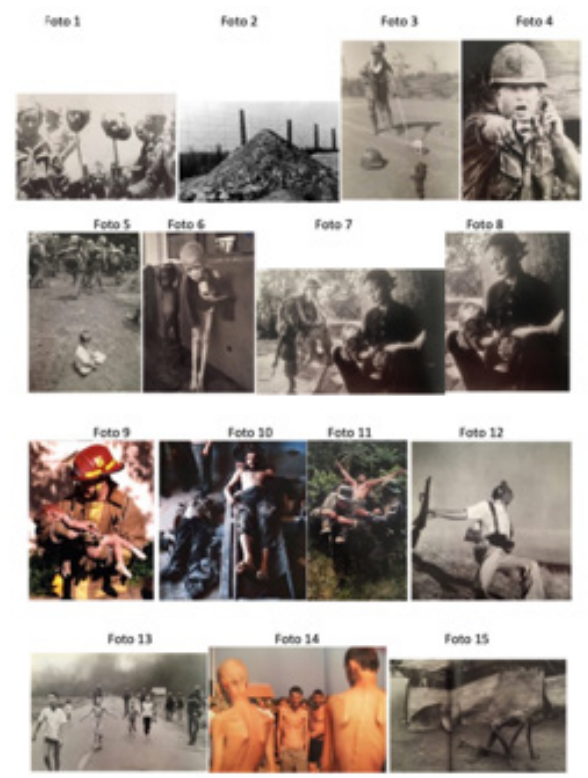

Figura 2. Corpus utilizado ${ }^{7}$

A implementação do estudo foi feita pelo Laboratório de Neuromarketing da FGV-SP, sob coordenação de Carlos Augusto Costa, que utilizou equipamentos da empresa SMI (SensoMotoric Instruments), de São Paulo. A seleção das imagens foi feita a partir do corpus da tese (com cerca de 150 imagens), reduzindo para um número de fotos adequado para as condições do estudo. Assim, foram incluídas 15 fotografias. A equipe do Neurolab da FGV selecionou as 12 pessoas que se submeteram ao teste ${ }^{8}$. O equipamento é composto de um computador laptop sobre cuja tela, na parte superior, é acoplado um sensor que identifica com exatidão os movimentos dos olhos do observador (exatamente para que ponto da tela ele está olhando a cada instante) em tempo real à medida em que as 15 imagens são apresentadas em sequência, trocando a cada 5 segundos. 
O teste revelou que o ponto fulcral da atenção dos observadores é sempre um rosto, se houver, mesmo que ele seja o de um bebê que ocupa um pequeno espaço da mancha fotográfica. Nas imagens em que há dois rostos, a atenção se divide; nas fotos em que havia mais de dois rostos, o olhar deixou um ou mais rostos de fora e se concentrou em um rosto apenas, em dois casos, e nos rostos de duas pessoas decapitadas e de um soldado, em outro.

A imagem de uma caveira parece ser particularmente atraente, funcionando como um rosto. No caso da foto de um soldado que empurra com uma vara uma caveira para servir de espantalho, em uma estrada do Camboja, a caveira divide os olhares com o rosto do soldado. Já no caso do monte de ossos encontrado pelos soldados russos que chegaram ao campo de concentração nazista de Majdanek (na Polônia), os olhos se concentram em três caveiras que se destacam entre os restos humanos.

Estudo anterior (BINDEMANN, 2010) realizado sobre o comportamento do olhar das pessoas em relação a fotografias indica que, nos casos em que é difícil localizar um corpo humano em uma imagem, o olhar busca a identificação pelo centro de gravidade do corpo, como se precisasse do formato dessa região para reconhecer a presença humana. Entre todas as fotos apresentadas, o olhar das pessoas pesquisadas se concentrou sobre o corpo todo acima da cintura (e não só no rosto) em dois casos de fotografias particularmente dramáticas: a da menina nua, queimada de napalm, que corre chorando por uma estrada do Vietnã; e no caso de um homem absolutamente esquálido, como uma espécie de esqueleto ainda vivo, que engatinha pelo chão em um campo de refugiados vítimas da longa guerra civil no Sudão. Neste caso, é preciso destacar que o rosto não está visível na fotografia. Em Todos os outros casos, o rosto é o ponto de atenção. Uma fórmula de emoção tradicional da iconografia antiga, recuperada pelas fotos de conflito contemporâneas, é a "Pietá". As fotos de consolação pelo abraço remetem ao arquétipo conhecido da escultura de Michelângelo, em que Maria segura o corpo de seu filho, Jesus. Entre as 15 imagens apresentadas aos pesquisados com equipamento de Eye Tracking, há duas fotografias que reproduzem essa imagem: um bombeiro uniformizado que segura o corpo de um bebê diante do prédio destruído por uma explosão em Oklahoma, em abril de 1995; e uma mulher vietnamita que segura um bebê no colo, à espera de atenção médica. Nos dois casos, os olhares se dividem entre os dois rostos, da criança vitimada e de seu protetor. 


\section{Considerações finais}

Na análise das reações dos espectadores usando ferramenta de reconhecimento facial de emoções, destacamos como principal resultado o constante crescimento da curva de engajamento, em um movimento ascendente consistente por todo o período em que as 25 fotos foram apresentadas. Isso quer dizer que, independentemente da potência emocional de cada imagem, uma após a outra, o engajamento se amplia. Esse comportamento é revelador de que imagens de conflito provocam envolvimento, que ele não varia substancialmente entre uma imagem e outra em uma sequência, e que cada imagem serve de escada para a seguinte, o que faz com que a linha de tendência, média, seja uma ascendente constante. O engajamento sobe continuamente, mesmo que algumas imagens tenham menor potência do que outras.

Destaca-se também o fato de que a repugnância é a principal emoção negativa ao longo da sequência de imagens, indicando uma reação de nojo ou asco a algumas imagens. Essa repugnância, no entanto, não reduz o engajamento, nem mesmo diante daquela foto identificada (no questionário quantitativo) como a mais repulsiva, a de um homem decapitado pela organização terrorista Estado Islâmico.

Ao mesmo tempo, emoções como tristeza, raiva e medo têm curvas descendentes, como se, após a exposição de algumas imagens, o espectador diminuísse sua reação negativa, enquanto persiste certa repulsa (em uma constante oscilante) e cresce o engajamento.

O comportamento combinado dessas emoções permite concluir que a exposição a uma série de imagens violentas produz um engajamento do sujeito, uma atração continuada, apesar da permanente manifestação de repulsa diante das imagens, ao mesmo tempo que sentimentos negativos se reduzem ao longo do tempo de exposição às imagens.

A conclusão a que chegamos é a de que as imagens violentas provocam adição, apesar de um constante sentimento de repulsa ou nojo, e esse desejo de mais imagens é acompanhado (ou possibilitado) pela redução progressiva de sentimentos negativos, como tristeza, raiva e medo.

Os resultados dos estudos mostram também que as imagens que envolvem crianças provocam uma atenção maior, o que se manifesta pela expressão mais intensa das diferentes emoções quando o sujeito é exposto a fotografias 
de crianças. São essas imagens os principais destaques de intensidade das emoções medo, raiva, surpresa, repugnância (duas fotos se destacam) e engajamento (duas fotos), no estudo de reconhecimento de emoções por expressão facial.

A intensa reação empática a fotos de crianças se manifesta também nos dois outros estudos realizados de forma combinada: no questionário da pesquisa quantitativa, fotos de crianças são apontadas como "impactantes" e "mais impactantes" e os rostos infantis surgem como "pontos de atenção" no estudo feito com Eye Tracking.

A potência das imagens com bebês e crianças pode ser constatada também no fato de que bebês retratados nas fotos são o centro da atenção ou dividem o foco do olhar com os adultos que Ihes prestam cuidados, em cenas que reproduzem uma "fórmula de emoção" (WARBURG, 2013) tradicional da iconografia antiga (recuperada pelas fotos de conflito contemporâneas), a "Pietá", imagem de consolação pelo abraço, em que o arquétipo mais conhecido é a estátua de Michelangelo, em que Maria segura o corpo de seu filho, Jesus. Entre as 15 imagens apresentadas aos pesquisados com equipamento de Eye Tracking, há duas fotografias que reproduzem essa imagem: um bombeiro uniformizado que segura o corpo de um bebê diante do prédio destruído pela explosão de um caminhão bomba em Oklahoma, em abril de 1995; e uma mulher vietnamita que segura seu bebê no colo, à espera de atenção médica (nesse caso, a imagem foi cortada do fotograma original que incluía um soldado norte-americano vigiando mãe e filho). Nos dois casos, os olhares se dividem entre os dois rostos, da criança vitimada e de seu protetor.

O comportamento dos observadores no levantamento com a ferramenta Eye Tracking mostra que seu olhar é predominantemente atraído por rostos em todas as fotos em que eles estão presentes, mesmo quando o rosto é representado pela face de uma cabeça cortada ou até quando o elemento fotografado é uma caveira.

Um exemplo dessa atratividade do rosto como "ponto de atenção" em uma imagem é o fotograma original em que a mãe vietnamita segura seu bebê, como uma "Pietá". Nessa imagem completa, mãe e filho estão sob a vigilância de um soldado norte-americano fortemente armado. O fotograma completo foi apresentado entre as 15 imagens, além da imagem cortada (na qual só aparecem mãe e bebê). Diante da imagem original, o ponto que mais atraiu o olhar das pessoas submetidas ao teste foi o rosto do soldado norte-americano. 
A força de atração do rosto parece ser reafirmada também na atenção dedicada pelo olhar dos observadores a duas fórmulas de emoção de grande potência: caveiras, símbolo universal da morte; e cabeças cortadas, que despertam horror imediato, diante da aniquilação da pessoa, as duas imagens presentes em três das fotografias apresentadas.

Nesses casos de rostos mortos, uma caveira solta no pavimento de uma estrada disputa a atenção com o rosto do soldado que a conduz com uma vara; as caveiras são os elementos que mais chamam atenção, destacandose em uma infinidade de restos humanos acumulados, em monte de ossos, abandonados em um campo de concentração nazista na Polônia.

Da mesma forma, no caso da fotografia da Primeira Guerra Mundial, em que soldados espanhóis exibem a cabeça de dois rebeldes marroquinos espetadas na ponta de baionetas, também os rostos dos dois mortos disputam a atenção com o de um dos soldados.

A atenção ao rosto é menos intensa no caso da foto do "Comandante Zero", líder da guerrilha dos Contras, que enfrentava o governo sandinista da Nicarágua, nos anos 1980. O líder guerrilheiro aparece ferido, sendo carregado por soldados. Sua face ocupa um pequeno espaço da fotografia (menor do que o dos soldados que o carregam), mas é ele quem atrai atenção dos observadores, apesar de o foco do olhar envolver mais áreas em torno do rosto, do alto do tórax a toda a cabeça.

Por fim, o comportamento dos observadores nesta pesquisa não comprovou os estudos anteriores de Janik et al. (1978), que apontam que os olhos são o centro da atenção quando observadores miram o rosto de outros homens. Nas fotos de guerra apresentadas aqui, o olho não é o ponto fulcral da atenção, nem mesmo naquela imagem em que o militar norte-americano aponta o dedo e os olhos com grande energia para o espectador (conforme a imagem clássica do "gesto dêitico", uma fórmula de emoção arcaica explorada em cartazes de convocação de soldados voluntários desde a Primeira Guerra Mundial, conforme Ginzburg, 2014). Nessa foto, que neste estudo recebeu um corte que a deixou semelhante aos cartazes de mobilização de voluntários para a luta armada, em que um militar aponta para o observador junto a slogans como "Você tem um dever a cumprir", a mancha que revela o olhar do observador envolve os olhos, mas também a boca que grita.

Os estudos comprovam o poder de impacto da imagem de uma cabeça cortada como "ponto de atenção". A visão da imagem provoca impacto 
imediato, emoção incontrolável de "horror", como define Freud (2013) em ensaio sobre o mito grego da Medusa. Essa potência é descrita como tal em estudos sobre mitos arcaicos e na literatura clássica, que se atualiza em frequentes atentados terroristas contemporâneos, como é o caso da fotografia apresentada, de uma vítima da organização terrorista Estado Islâmico. Nas respostas ao questionário quantitativo, a fotografia de um homem decapitado pelo Estado Islâmico é apontada como a mais impactante. "Realista", "atual", "forte", "brutal" são adjetivos usados por eles para qualificar essa foto como a mais impactante do estudo. Também no estudo com Eye Tracking, as cabeças cortadas são o "ponto de atração" nas imagens em que aparecem.

\section{Discussão e possíveis desdobramentos}

1. A observação dos resultados dos três estudos confirma a impressão de Ekman de que os questionários quantitativos não refletem as emoções realmente despertadas pela visão das imagens, mas os respondentes tendem a submeter suas respostas àquilo que estão dispostos a contar aos outros sobre seus sentimentos, o que Ekman classificou como "pósracionalização", citando Peter Goldie (EKMAN, 2003, p. 39). Esse fato permite supor que haja duas camadas distintas de leitura com reações discrepantes: a reação imediata manifesta nos gestos faciais é bastante diferente daquela descrita em resposta ao questionário quantitativo. Essa "pós-racionalização" não só altera a potência da reação, como se poderia esperar pela distância temporal, mas também submete a descrição da emoção ao filtro do que o sujeito sente pertinente descrever. A relação diversa ou mesmo contraditória encontrada entre os resultados obtidos dos testes de reações automáticas, neurais ou "pré-racionalizadas", e as respostas aos questionários quantitativos, "pós-racionalizados", sugere a oportunidade de um estudo específico que possa revelar se há constantes nas discrepâncias dos resultados entre os diferentes sujeitos, que permita entender como as pessoas racionalizam suas reações automáticas, como elas identificam seus sentimentos imediatos de raiva, repugnância, tristeza etc.

2. Da mesma forma que o estudo sugere a necessidade de realizar outros experimentos para comprovar a hipótese de que a exposição dos sujeitos a imagens de violência provoca alguma forma de adição ou demanda por mais e mais imagens violentas, é conveniente realizar uma avaliação semelhante da simultânea queda dos sentimentos de tristeza, raiva e 
medo ao longo do tempo de exposição às imagens. Uma possibilidade de estudo é a exposição dos sujeitos a outras sequências de fotos de conteúdo semelhante para que se possa medir se o comportamento de redução da tristeza se manifesta também diante de outros conjuntos de fotografias violentas ou se o fenômeno ocorreu diante da sequência específica que foi montada no presente levantamento. A coincidência da redução consistente dos sentimentos de tristeza, raiva e medo, ao mesmo tempo em que o engajamento se mantém crescente, sugere que, para se manifestar, a adição necessita ao mesmo tempo de um sentimento de excitação e de uma redução da percepção de emoções negativas. Essa reação combinada pode se confundir com prazer e se traduzir em alguma forma de dependência ou adição. Essa hipótese precisa ser testada em próximos estudos.

Leão Serva é professor de Ética Jornalística no curso de Jornalismo e pesquisador do Media Lab da ESPM-SP. É mestre e doutor em Comunicação e Semiótica pela PUC-SP, jornalista, e diretor de Jornalismo da TV Cultura-SP (emissora educativa da Fundação Padre Anchieta).

leao.serva@espm.br

Eduardo Eugenio Spers é professor titular do departamento de Economia, Administração e Sociologia da Universidade de São Paulo (USP), Campus Esalq. Realizou pós-doutorado na Wageningen University (WUR), Holanda, com especialização no IGIA, França, e doutorado em Administração pela Universidade de São Paulo (USP).

edespers@usp.br

Norval Baitello Jr é professor titular no Programa de Estudos Pós-Graduados em Comunicação e Semiótica da Pontifícia Universidade Católica de São Paulo (PUC-SP). É doutor em Comunicação pela Freie Universität, de Berlim. Recebeu o Prêmio Maturidade Acadêmica da Intercom (2015).

norvalbaitello@pucsp.br 
Carlos Augusto Costa é engenheiro eletrônico, diretor adjunto da Fundação Getúlio Vargas (FGV-SP), coordenador do Laboratório de Neuromarketing. É gerente executivo e doutorando em Administração de Empresas no Instituto Universitário de Lisboa (ISCTE-IUL, Lisboa).

carlos.augusto.costa@fgv.br

Contribuições de cada co-autor: Leão Serva: concepção do Projeto de Pesquisa, seleção do corpus de imagens, coordenação dos campos e redação do texto final; Eduardo Spers: fundamentação teórica e metodologia, supervisão na análise dos resultados e organização e relato das conclusões; Norval Baitello: orientação na concepção do Projeto e análise dos primeiros resultados; Carlos Augusto Costa: implementação do estudo com Eye Tracking.

\section{Legendas das fotos}

\section{Figura 1:}

Foto 1: Gravura “Dança Macabra” (1486) de Guyot Marchant.

Foto 2: Gravura "Maria Madalena", de Gustave Doré.

Foto 3: Fotografia: Palácio de Secundrabagh (Índia), logo após o "Motim Indiano" (1858), de Felice Beato.

Foto 4: Pilha de ossos e caveiras humanas encontrada pelos soldados do Exército Vermelho soviético ao conquistar o campo de concentração nazista em Majdanek (Polônia), em 1944.

Foto 5: Soldado do governo do Camboja dispõe uma caveira como espantalho durante o avanço das tropas da guerrilha Khmer Rouge rumo à capital Phnom Penh. Foto de Sou Vichith (ag. Gamma), 1973.

Foto 6: Exposição das cabeças de Lampião (embaixo, em primeiro plano), Maria Bonita (logo acima dele) e dos outros membros do grupo cangaceiro mortos pela polícia em Sergipe, em 1938. Autor desconhecido. Acervo IMS.

Foto 7: Cabeças de rebeldes marroquinos cortadas por soldados espanhóis durante a Primeira Guerra Mundial. No livro War Against War, de Ernst Friedrich, 1924.

Foto 8: Jornalista britânico David Haines foi feito refém e depois morto e decapitado pela organização terrorista Estado Islâmico (conhecida pela sigla ISIS), na Síria, em 2014. Imagem de vídeo do ISIS. 
Foto 9: "Davi com a cabeça de Golias" (1609-10), pintura de Michelangelo de Caravaggio (1571-1610).

Foto 10: “Salomé com a cabeça de João Batista” (1506-7), pintura de Andrea Solario (14601524).

Foto 11: Fuzileiro naval dos EUA em missão contra a guerrilha Vietcongue. Foto de Larry Burrows, Revista Life, outubro, 1966.

Foto 12: Garoto vietnamita assustado durante bombardeio de sua aldeia. Detalhe da fotografia com que Kyoichi Sawada ganhou o Pulitzer de 1966.

Foto 13: Soldado norte-americano se esconde em uma plantação de arroz para se proteger de ataque da guerrilha Vietcongue. Detalhe de foto de Henri Huet, 1966.

Foto 14: O pintor Pablo Picasso observa o corpo de um homem morto na guerra da Coréia. Museu Picasso, Barcelona.

Foto 15: Soldado norte-americano congelado pelo medo sob bombardeio na cidade Hue, Vietnã. Foto de Don McCullin, 1968.

Foto 16: Princesa Diana com uma criança vítima da Aids em Angola.

Foto 17: Soldado norte-americano salva bebê de uma caverna onde a mãe havia se escondido com ela, na ilha japonesa de Saipan, na Segunda Guerra Mundial. Foto de W. Eugene Smith, Revista Life (1945).

Foto 18: Papa João Paulo $2^{\circ}$ segura Monik, 3 anos, e sua pequena irmã Zin, 1 ano, em uma visita a Madagascar, em 1989.

Foto 19: A escultura "Pietá" ou "Piedade" (1499), do artista renascentista italiano Michelangelo Buonarroti. Museu do Vaticano.

Foto 20: Pai ferido segura o filho, também machucado por bombardeios cruzados do exército do Vietnã do Norte à cidade de Hue. Foto de Don McCullin, 1968.

Foto 21: A menina sul-vietnamita Kim Phúc corre nua, com o corpo em chagas causadas pelo napalm em bombas disparadas por engano por aviões norte-americanos sobre sua aldeia, em junho de 1972. Foto de Nick Ut / The Associated Press.

Foto 22: Menina vietnamita carrega parte de seus pertences durante a fuga da família de uma zona de guerra.

Foto 23: O pai de etnia albanesa coloca o filho morto no caixão onde seria enterrado, durante o início da guerra civil no Kossovo (ex-lugoslávia), em 1998. Foto de Yannis Behrakis/Reuters.

Foto 24: Menino com o braço destroçado chora ao ver a mãe morta, depois que um míssil da guerrilha Khmer Rouge explodiu sobre o mercado de Pochentong, no Camboja, em 28/2/1975. 
Foto 25: Criança vietnamita chora, abandonada, enquanto os soldados norte-americanos vasculham a aldeia em busca de guerrilheiros vietcongues, em 1966.

\section{Figura 2:}

Foto 1: Cabeças de rebeldes marroquinos cortadas por soldados espanhóis durante a Primeira Guerra Mundial. No livro War Against War, de Ernst Friedrich, 1924.

Foto 2: Pilha de ossos e caveiras humanas encontrada pelos soldados do Exército Vermelho soviético ao conquistar o Campo de Concentração nazista em Majdanek (Polônia), em 1944.

Foto 3: Soldado do governo do Camboja dispõe uma caveira como espantalho durante o avanço das tropas da guerrilha Khmer Rouge rumo à capital Phnom Penh. Foto de Sou Vichith (ag. Gamma), 1973.

Foto 4: Durante um ataque da guerrilha vietcongue, o líder de uma unidade militar norte-americana grita ordens aos comandados. Detalhe de fotografia de Oliver Noonan (1969).

Foto 5: Criança vietnamita chora, abandonada, enquanto os soldados norte-americanos vasculham a aldeia em busca de guerrilheiros vietcongues, em 1966.

Foto 6: Menino albino, Guerra Civil de Biafra (Nigéria, 1967). Don McCullin.

Foto 7: Mãe vietnamita segura o filho ferido sob o olhar de soldado norte-americano. Foto de Philip Jones Griffiths (1967)

Foto 8: Mãe vietnamita segura o filho ferido (detalhe) de foto de Philip Jones Griffiths (1967)

Foto 9: O bombeiro Chris Fields segura o bebê Baylee Almon, já morto, vítima do ataque terrorista à sede de edifício do poder público em Oklahoma (1996). Foto de Charles Porter, ganhadora do Prêmio Pulitzer daquele ano.

Foto 10: O corpo do argentino Che Guevara, líder guerrilheiro da revolução cubana (1959), é exposto morto na Bolívia em outubro de 1967.

Foto 11: Guarda-costas do Comandante Zero, líder da guerrilha "Contra", é levado por companheiros depois de ferido em combate na Nicarágua em 1984. Foto de James Nachtwey.

Foto 12: "Instante da morte" (ou "Soldado republicano morrendo"), foto de Robert Capa (1936) na Guerra Civil Espanhola.

Foto 13: A menina sul-vietnamita Kim Phúc corre nua, com o corpo em chagas causadas pelo napalm em bombas disparadas por engano por aviões norte-americanos sobre sua aldeia, em junho de 1972. Foto de Nick Ut / The Associated Press.

Foto 14: Muçulmanos-bósnios no campo de prisioneiros de Trnopolje, dominado por militares sérvios, durante a guerra civil da Bósnia (1992-1995). Fotografia de Ron Haviv.

Foto 15: Vítima da fome em campo de refugiados no Sudão (1993). Foto de James Nachtwey. 


\section{Referências}

BINDEMANN, M. et al. Face, Body and Center of Gravity Mediate Person Detection in Natural Scenes. Journal of Experimental Psychology: Human Perception and Performance, n.36 (6), p. 1477. Washington, DC: American Psychological Association, 2010.

DARWIN, C. A expressão das emoções no homem e nos animais. São Paulo: Companhia das Letras, 2013.

DE WAAL, F. A Era da Empatia. São Paulo: Companhia das Letras, 2010.

DIMBERG, U.; THUNBERG, M.; ELMEHED, K. Unconscious facial reactions to emotional facial expressions. Psychological Science 11, pp 86-89. Washington, DC: Association for Psychological Science (APS), 2000.

DUCHENNE, G.-B. Mécanisme de la physionomie humaine, ou Analyse électrophysiologique de l'expression des passions. Paris: Baillière, 1862.

EKMAN, P. Emotions Revealed. Nova York: Times Books, 2003.

FREUD, S. A Cabeça de Medusa. In: CHAVES, E. A cabeça de Medusa, de Sigmund Freud. Clínica \& Cultura, v. 2, n. 2, jul.-dez. 2013, p. 91-93. Disponível em: <http://seer. ufs.br/index.php/clinicaecultura/article/download/1938/1698>. Acesso em: 9 mai. 2021.

GALLESE, V. Being like me: self-other identity, mirror neurons, and empathy. In: HURLEY, S.; CHATER, N. (eds.). Perspectives on imitation. Págs. 101-8. Cambridge, EUA: MIT Press, 2005.

GINZBURG, C. Medo, Reverência, Terror. São Paulo: Companhia das Letras, 2014.

GOLDIE, P. The Emotions. Oxford: Oxford University Press, 2000.

HURLEY, S.; CHATER, N. (eds.). Perspectives on imitation. Págs. 101-8. Cambridge, EUA: MIT Press, 2005.

JAMES, W. What is an Emotion? (e-book) Nova York: SimonAndSchuster.com, 2013.

PLUTCHIK, R. What is an Emotion?. The Journal of Psychology: Interdisciplinary and Applied, vol. 61:2, p. 295-303. Londres: Taylor\& Francis, 1965. Disponível em <http://dx.doi. org/10.1080/00223980.1965.10543417>. Acessado em: 26. dez. 2020.

SERVA, L. A "Fórmula da Emoção" na Fotografia de Guerra: Como as imagens de conflitos se relacionam com a tradição iconográfica explorada por Aby Warburg. Tese de Doutorado. Programa de Pós-Graduação em Comunicação e Semiótica, PUC-SP, 2017.

SERVA, L. et al. Fotos de guerras causam dependência? Um estudo com reconhecimento facial de emoções. Discursos Fotográficos, v.16, n.28, jan/jun 2020, p. 66-92. Londrina: UEL, 2020.

SORCI, M., et al. Modelling Human Perception of Static Facial Expressions. Image and Vision Computing, n. 28.5, p. 790-806. Amsterdã: Elsevier, 2010. 
TULLIS, T.; WOOD, L. How many users are enough for a card-sorting study. Proceedings UPA, vol. 2004. Minneapolis (EUA): Usability Professionals Association (UPA), 2004.

WARBURG, A. A Renovação da Antiguidade Pagã. Rio: Contraponto/Museu de Arte do Rio, 2013.

El Atlas de Imágenes Mnemosine, 2 Vols. Org. Linda Báez Rubi. Coyoacan (MEX): UNAM, Instituto de Investigaciones Estéticas, 2012.

Artigo recebido em 15/03/2021 e aprovado em 06/06/2021. 